\title{
\begin{tabular}{l|l} 
pcori). & PATIENT-CENTERED OUTCOMES RESEARCH INSTITUTE \\
RESEARCH SUMMARY
\end{tabular}
}

PROJECT INFORMATION

April 2018

\section{Developing an Item Bank of Survey Questions to Measure Women's Experiences with Childbirth in Hospitals}

Principal investigator

Kimberly D. Gregory, MD, MPH
Organization

Cedars-Sinai Medical Center

\section{What was the research about?}

Understanding patients' expectations and their experiences can help hospitals improve care. Hospitals often send surveys to patients to ask about their care. To create surveys quickly, hospitals sometimes pick questions from an item bank. An item bank is a list of survey questions available to use about a specific topic.

In this study, the research team created an item bank about childbirth care. The team used the item bank to create and carry out a survey about women's preferences and experiences with care during and after childbirth. The team looked at which questions related closely to women's overall ratings of their hospital care.

\section{What were the results?}

The item bank had 100 questions about the care women prefer or how they felt after childbirth. For example, there were questions about managing pain during childbirth and making decisions about breastfeeding. The item bank also had 60 questions about women's personal traits, such as age or education level.

Using the results of a survey created from the item bank, the research team made a list of questions that related most closely to women's ratings of their care. This list included questions about how well staff communicated and showed concern and respect. Women's responses to questions about managing pain and some personal traits also related closely to their ratings of care.

\section{Who was in the study?}

The study included 2,757 adult women who were at least 20 weeks pregnant. The women were racially and ethnically diverse and lived across the United States. Of these women, 38 percent had at least some college education. The women spoke English or Spanish.

\section{What did the research team do?}

To create the item bank, the team looked at existing surveys to find questions about women's experiences with childbirth care. The team grouped 5,902 questions into 19 topics. When questions were similar, the team picked the best question.

The research team gave the survey to women when they were pregnant and again after they gave birth.

Community members, advocates for pregnant women, doctors, and nurses gave input to the study.

\section{What were the limits of the study?}

The item bank had questions about cesarean delivery. The item bank also had questions about places other than hospitals where women give birth. However, not many people responded to these questions. In addition, there were no questions about care during pregnancy or after going home from the hospital. 
Future studies could test questions about care for patients who have cesarean delivery. Studies can also see if hospitals can easily use the item bank questions.

\section{How can people use the results?}

Hospitals can create surveys from the item bank to learn about women's experience with childbirth care.
Hospitals can use what they learn to help improve care.

To learn more about this project, visit pcori.org/Gregory069. 